\title{
A ISO 9001 E A EDUCAÇÃO A DISTÂNCIA: CONTRIBUIÇÕES PARA A QUALIDADE NO ENSINO SUPERIOR
}

\author{
SÃO PAULO/SP JUNHO/2018
}

\author{
Francisco Carlos Tadeu Starke Rodrigues - Belas Artes - francisco.starke@belasartes.br \\ Jacqueline de Oliveira Lameza - Belas Artes - jacqueline.lameza@belasartes.br \\ Leila Rabello de Oliveira - Belas Artes - leila.rabello@belasartes.br \\ Lucas de Mattos Millan - Belas Artes - lucas.millan@belasartes.br \\ João Tenório da Silva - Belas Artes - joao.tenorio@belasartes.br
}

Tipo: Relato de Experiência Inovadora (EI)

Categoria: Métodos e Tecnologias

Setor Educacional: EDUCAÇÃO SUPERIOR

\begin{abstract}
RESUMO
O artigo apresenta um panorama nas relações entre as Instituições de Ensino Superior no Brasil e a nova Norma Brasileira ABNT NBR 15419 - Sistemas de gestão da qualidade - Diretrizes para a aplicação da ISO 9001 em organizações educacionais. A garantia da melhor prestação de serviços a partir de um Sistema de Gestão de Qualidade num ambiente universitário, alia-se a critérios de avaliação e a padrões de qualidade implementados pelo Ministério da Educação para o Ensino Superior Privado.
\end{abstract}

Palavras-chave: ISO 9001. Sistemas de qualidade. Ensino superior. EaD. Educação a Distância. 


\section{CONSIDERAÇÕES INICIAIS}

De maneira análoga à frenética realidade tecnológica de nossa contemporaneidade, a Educação a Distância no Brasil passa por constantes transformações e quebras de paradigmas que exigem frequentes redefinições e atualizações conceituais por parte de seus profissionais. Isto é particularmente verdadeiro quando tentamos definir qualidade em Educação a Distância, já que esta "exige um olhar amplo, sistêmico e que considere sua multiplicidade de significados e aspectos." (TARCIA, 2017).

A última grande mudança veio com o Decreto no 9.057, de 25 de maio de 2017, que reduz, de maneira considerável, as exigências para a oferta de cursos na modalidade a distância. Por exemplo, agora instituições públicas estão automaticamente autorizadas a ofertá-los, enquanto que instituições privadas podem ser credenciadas exclusivamente para ofertar cursos a distância (BRASIL, 2017). Esta maior leniência por parte dos órgãos reguladores potencializará o já sustentável crescimento da oferta de cursos EaD.

Ante esse cenário, pode-se dizer que a Educação a Distância brasileira deixa um período de supervivência para entrar em um período de aperfeiçoamento. No caso, deixa-se de visar a viabilidade e foca-se na qualidade. Portanto, torna-se imperativo que as IES definam e desenvolvam parâmetros capazes de distingui-las como instituições que trabalham para elevar o status da EaD em âmbito nacional.

Essa necessidade evidencia-se no relato dos profissionais do setor recolhido no Censo EaD Brasil 2016. As maiores dificuldades que o setor enfrenta atualmente encontram-se na inovação em abordagens pedagógicas e em tecnologia, no engajamento do corpo docente, nos processos administrativos e no desenvolvimento de infraestruturas de alto padrão. Quando as comparamos com as maiores dificuldades relatadas em anos anteriores, percebemos uma maturação da imagem da EaD tanto por parte das instituições quanto por parte dos alunos.

No caso dos alunos, a aceitação é ainda mais evidente, com uma massificação da demanda por cursos que abrangem todas as áreas do conhecimento: "o Censo EAD.BR 2016 contabilizou 561.667 alunos em cursos regulares totalmente a distância, 217.175 em cursos regulamentados semipresenciais, 1.675.131 em cursos livres não corporativos e 1.280.914 em cursos livres corporativos." (ABED, 2017). Também deve-se destacar a maior abrangência sobre o território nacional. Dito isso, e apesar da crescente oferta de cursos a distância por instituições públicas, $91 \%$ dos matriculados pertencem a instituições privadas.

Ante a saúde do setor, a alta competitividade, a maior abrangência territorial e os perigos da massificação, exige-se, portanto, maior foco na qualidade do ensino ofertado.

\section{OS BENEFÍCIOS DA CERTIFICAÇÃO ISO 9001}

As normas de qualidade asseguram as características desejáveis de produtos e serviços, como qualidade, segurança, confiabilidade, eficiência, intercambialidade, bem como respeito ambiental - e tudo isto a um custo econômico (ABNT, 2018). Porém, o ato de fornecer produto ou serviço que não siga a norma aplicável implica em esforços adicionais em um mercado competitivo.

Segundo a ABNT (2015), as normas: (1) tornam o desenvolvimento, a fabricação e o fornecimento de produtos e serviços mais eficientes, mais seguros e mais limpos; (2) facilitam o comércio entre países, tornando-o mais justo; (3) fornecem aos governos uma base técnica 
para saúde, segurança e legislação ambiental, e avaliação da conformidade; (4) compartilham os avanços tecnológicos e a boa prática de gestão; (5) disseminam a inovação; (6) protegem os consumidores e usuários em geral, de produtos e serviços; e (7) tornam a vida mais simples provendo soluções para problemas comuns.

A Norma ISO 9001:2015, por exemplo, emprega a abordagem de processo, que incorpora o ciclo Plan-Do-Check-Act (PDCA). A sigla PDCA - onde a letra P (plan: planejar), a D (do: fazer, executar), a C (check: verificar, controlar), e a A (act: agir, atuar corretivamente) compõe o ciclo PDCA, e é aplicada no uso de estatísticas e métodos de amostragem. É uma ferramenta que representa o ciclo de gerenciamento de uma atividade e a abordagem de processo habilita uma organização a planejar seus processos e suas interações. O ciclo PDCA habilita uma organização a assegurar que seus processos tenham recursos suficientes e sejam gerenciados adequadamente, e que as oportunidades para melhoria sejam identificadas e as ações sejam tomadas.

A série de normas ISO 9000 recebe críticas do ponto de vista de sua exigência de formalização e documentação; implantar a norma seria um processo direcionado para o papel. Entretanto, é possível refutar essa ideia com base em algumas evidências. Withers e Ebrahimpour (2000) acreditam que a gestão das empresas percebe os fatores intrínsecos à ISO 9000 como fatores importantes para o sucesso e a vantagem competitiva. Operar uma empresa de acordo com o modelo de gestão por processos, tal como preconizado pela ISO 9001, reduz o tempo de desenvolvimento de novos produtos, os problemas de início de produção e os custos em geral (DIMARA et al., 2004), melhorando a eficiência dos processos internos (SANTOS; ESCANCIANO, 2002).

A norma ISO 9001 é de aplicação voluntária e pode ser adotada como um padrão normativo dentre outros que existem no mundo. Desta forma, segundo Rodrigues et al. (2008), a ISO 9001 passa a ser percebida como um requisito de mercado, tendo se fixado como a mais importante referência mundial para requisitos da qualidade nas transações B2B (Business to Business)

Todavia, se uma empresa implanta a ISO 9001, por que ela precisaria se certificar? A certificação atua como um sinal de atributos superiores, mas não observáveis, de qualidade, que propiciaria um benefício competitivo. A análise dos preceitos formulados por Akerlof (1970), com seu artigo seminal Market for lemons, é fundamental para este entendimento. Quando existe informação assimétrica, o consumidor seleciona os produtos de forma adversa no momento da compra. A sinalização é um ambiente em que as partes revelam as suas informações (MILGROM; ROBERTS, 1992, p. 154-155). Há uma relação positiva entre sinalização e reputação. A sinalização pode ser feita por meio de certificados (PINDYCK; RUBINFELD, 1999, p. 680). Ao se conquistar reputação, aumenta-se a participação de mercado e a rentabilidade.

A certificação ISO 9001, portanto, atua como um sinal para o mercado, distinguindo empresas certificadas das não certificadas (ANDERSON; DALY; JOHNSON, 1999) e propiciando um prêmio no preço e aumento no volume de vendas. Terlaak e King (2006) ressaltam que estudos anteriores falharam em explicar - em sua totalidade - a natureza das normas de gestão da qualidade. Falharam em não explicar, do ponto de vista teórico, por que motivo uma 
empresa adicionaria maiores problemas ao seu cotidiano e mais despesas para obter uma certificação oficial não compulsória. Argumentam que, se as normas são públicas e as empresas de consultoria estão disponíveis para auxiliar na sua adoção, elas não necessitariam se certificar para gozar desse benefício operacional.

Isto é, o que poderia explicar o porquê da sinalização propiciar um grande benefício às empresas? A resposta parece residir na seguinte lógica: (1) empresas sinalizam mais e melhor as características "invisíveis" de seus produtos e serviços aos seus clientes, (2) reduzindo, assim, a informação assimétrica que (3) detém ou mitiga a seleção adversa que (4) promove melhoria da imagem da empresa, (5) aumentando a sua reputação e, consequentemente, (6) aumentando as suas vendas e seus retornos, com diminuição de custos.

Neste caso em tela, ou seja, a certificação da Educação a Distância do Centro Universitário Belas Artes de São Paulo, propõe-se apresentar os ganhos obtidos com a mesma, inclusive do que foi o motivador e o ineditismo da conquista.

\section{A CERTIFICAÇÃO NA EAD BELAS ARTES}

Para expandir sua atuação no setor educacional e se adequar às novas demandas de mercado, o Centro Universitário Belas Artes de São Paulo criou o Departamento de Educação a Distância, unidade institucional responsável pela gestão dos processos administrativos e pedagógicos de cursos e atividades educacionais na modalidade a distância, conforme define Silva (2013). Desde o seu credenciamento, a preocupação com a qualidade do serviço prestado norteou todo o trabalho, culminando na Certificação ISO 9001 adquirida dezembro de 2017, conforme itens elencados a seguir.

\subsection{Concepção, autoria, desenvolvimento instrucional e design de conteúdo}

O nosso fluxo de produção EaD tem como base o modelo de design instrucional fechado. Segundo Filatro (2008), este é o modelo onde o Designer Instrucional começa a trabalhar em uma tela vazia e toma todas as decisões mediante critérios institucionais qualiquantitativos claros e inalteráveis.

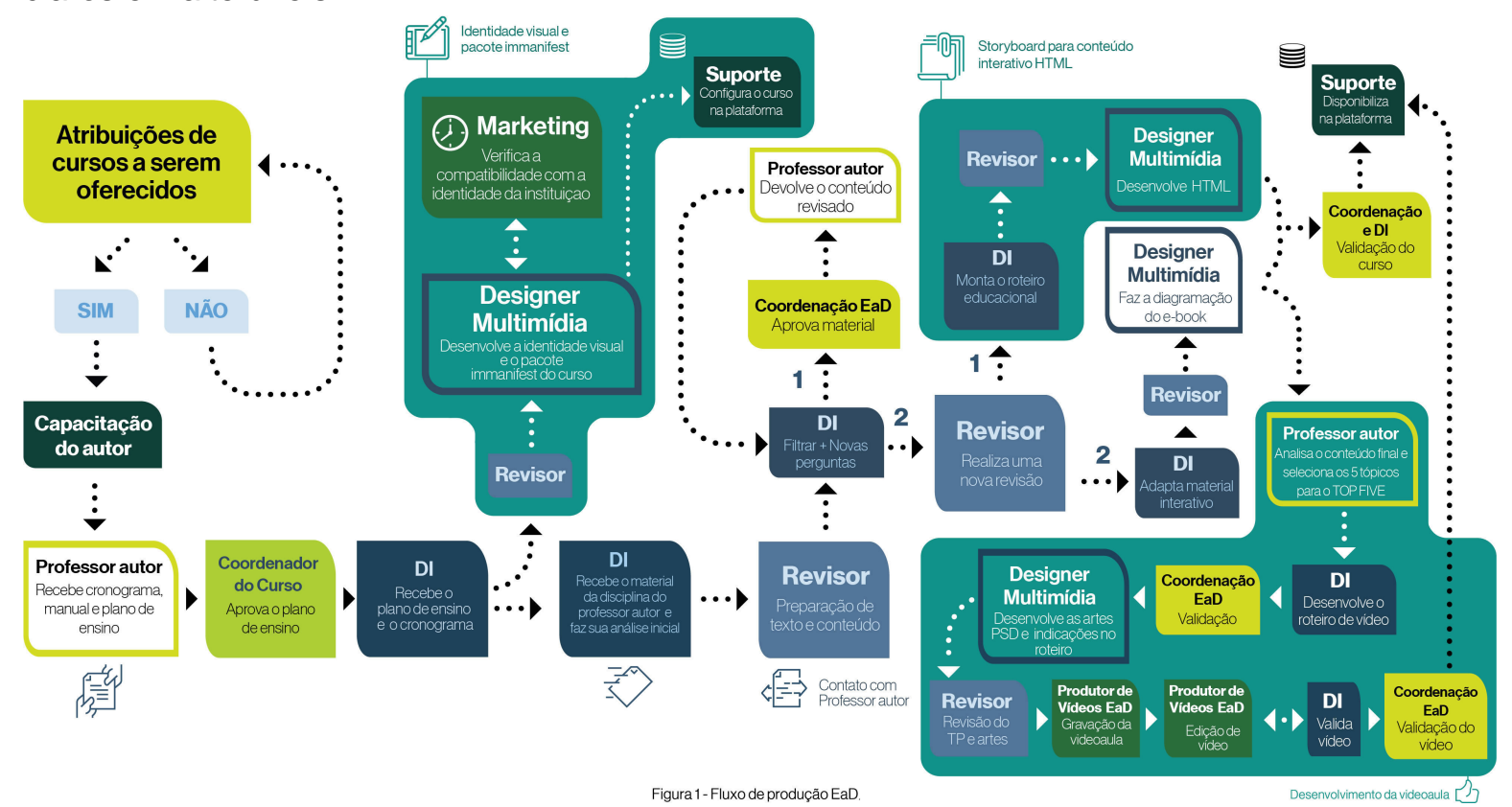


A seleção de quais disciplinas $\mathrm{EaD}$ e/ou cursos $\mathrm{EaD}$ serão produzidos é feita pela Reitoria. A partir deste momento, tem início o trabalho da equipe multidisciplinar do Departamento de Educação a Distância. O autor é indicado pelas Pró-Reitorias e Coordenadores de Curso, e somente iniciará a autoria após participar da capacitação como Professor Autor. Para a capacitação do autor foi desenvolvido o Manual do Professor Autor que, detalhadamente, ensina o professor sobre como ele deve produzir desde o Plano de Ensino até como deve ser a linguagem utilizada durante a elaboração do texto-base e das atividades requeridas a fim de que se cumpra a carga horária estipulada. O Professor Autor recebe o cronograma de trabalho, cuja primeira tarefa é a elaboração do Plano de Ensino. Estando este dentro do padrão, é encaminhado ao Coordenador do Curso para aprovação.

O Plano de Ensino aprovado é encaminhado ao Revisor de Textos e ao Designer Multimídia, que desenvolve a identidade visual da disciplina, cuja coesão às diretrizes institucionais deve ser aprovada pelo Departamento de Marketing. Paralelamente, a equipe de suporte técnico inicia a preparação da plataforma para receber o novo curso.

Seguindo a entrega por etapas previstas pelo cronograma, o Designer Instrucional, que assume um papel de gestor do projeto, realiza análises iniciais e alterações pertinentes ao conteúdo recebido do autor. Seu propósito, indo além de simplesmente deixar o material mais agradável ou divertido - o que muitas vezes é pouco eficiente para a aprendizagem - é esclarecer todas as complexidades de relações do conteúdo, como afirma Carolei (2015), segundo a qual cabe ao DI ajudar o autor a mapear o texto e escolher o nível de conteúdo que é possível atingir com o material. Ele então encaminha o material ao Revisor e Preparador de Textos, cuja análise visa garantir o bom português e a clareza da informação, além da natureza leve e dialógica que o texto de cursos EaD deve ter, segundo Franco (2007), a fim de envolver o aluno no processo de aprendizagem através do texto. A cada devolutiva do autor, há uma nova revisão. Esta primeira fase de tratamento do material culmina com a aprovação da Coordenação EaD. Passa-se, então, ao desenvolvimento do storyboard, que serve como roteiro da produção do HTML, com ênfase em suas interatividades e na natureza colaborativa da produção, concordando, assim, com Carolei (2015). Como são necessários alguns ajustes durante a fase de produção multimídia e, por vezes, durante a alteração de parte do texto, outra etapa de revisão se faz necessária. Somente após a nova etapa de revisão, é que o storyboard é enviado ao Designer Multimídia para o desenvolvimento das telas em HTML5, que denominamos de Easy Scroll Interativo. Telas totalmente responsivas para que nossos alunos possam acessar de qualquer computador e/ou dispositivo móvel. Pensando nos alunos que preferem estudar off-line, a equipe multidisciplinar desenvolve o mesmo conteúdo no formato $e$ book, o qual também passa por revisão.

Conteúdo pronto, hora de produzir as respectivas videoaulas, das quais o autor é protagonista, a fim de reforçar o elo entre conhecimento e aluno. Por isso, é de sua responsabilidade redigir o texto - que será preparado pelo Revisor e transformado em Roteiro Técnico pelo DI —, o qual guiará os gráficos e animações que reforçarão a apreensão do conteúdo, de acordo com Cordeiro (2007), quando afirma que a imagem midiática demonstra, mais do que a palavra, provocando afeto e emoções por meio de suas imagens e sons. Após a aprovação da Coordenação EaD, o Roteiro Técnico passa por revisão de texto, minimizando a necessidade 
de alterações in loco. Durante a gravação, realizada nos estúdios de nosso Laboratório de Imagem e do Som (LIS), o Professor Autor é dirigido pedagogicamente pelo Designer Instrucional e acompanhado pelo Revisor de Textos, que controla o teleprompter a fim de certificar-se de que o conteúdo será dito corretamente e de dinamizar qualquer alteração de última hora. A direção geral é feita pelo nosso Produtor de Vídeos EaD, responsável pela iluminação, captação de imagens, edição, animação e finalização. Uma vez finalizada, a videoaula passa pela validação do Designer Instrucional e, depois, da Coordenação EaD. Se tudo estiver dentro dos padrões de qualidade exigidos e normatizados, ocorre a liberação na plataforma.

Para cada um dos profissionais destacados no fluxo de produção, há um manual com o passo a passo de suas atribuições. Assim, quando um profissional se ausenta ou é desligado, outro profissional é capaz de assumir seu papel sem que haja prejuízo na quantidade e qualidade dos materiais produzidos.

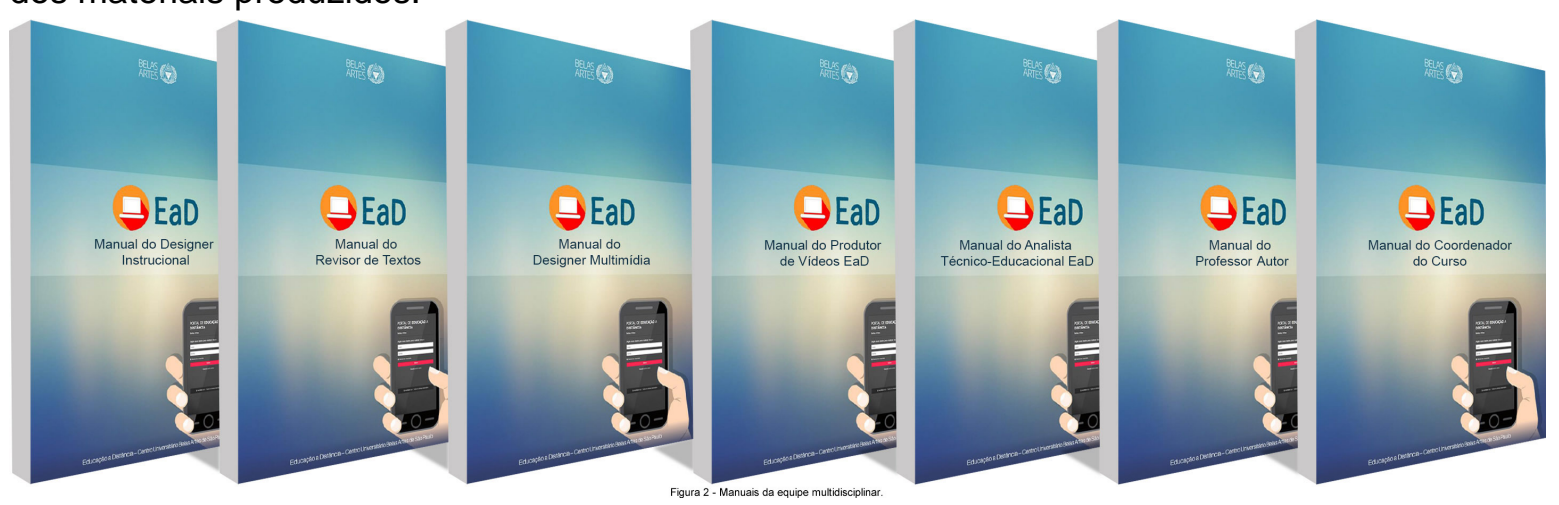

No Centro Universitário Belas Artes, a concepção, autoria, desenvolvimento instrucional e design de conteúdo, um dos itens com certificação ISO 9001, busca direcionar todas as etapas do processo produtivo à eficiência e à qualidade. Isso somente é possível por meio de uma "separação integrada" do fluxo de trabalho, considerando a função de cada profissional vinculado de maneira ao mesmo tempo individual e coletiva; compreendendo a especificidade de cada mídia trabalhada e suas exigências estilísticas e técnicas, além da responsabilidade pela qualidade do conteúdo produzido. Em suma, a Belas Artes tem ciência dos desafios de produção de material didático e, por isso, procura otimizá-la ao máximo.

\subsection{Serviços de tutoria on-line para modelos convencionais e híbridos}

No Centro Universitário Belas Artes de São Paulo, a tutoria EaD é composta exclusivamente por docentes contratados em nossos cursos de graduação e pós-graduação presenciais. Ao serem indicados pelos Coordenadores de Cursos para assumirem a nova tarefa, passam por um curso de Formação de Tutores EaD de 40 horas, com momentos presenciais e a distância. A fim de corrigir possíveis desvios, são constantemente acompanhados ao longo do semestre. O Manual do Tutor EaD é completo, uma vez que além de detalhar o funcionamento da plataforma e explicar o sistema de notas e faltas, apresenta simulações de como devem ocorrer as mediações de fóruns e chats e de como devem ser redigidos os feedbacks, corroborando com Lameza (2017), quando afirma que, ao ser contratado para atuar como Tutor EaD, muitos são os desafios desse profissional. Além da formação inicial e do acompanhamento diário, ao iniciar cada etapa, o Tutor EaD recebe as instruções da 
Coordenação EaD sobre quais são suas atividades ao longo daquele período, o padrão a ser seguido e as datas-limite para cada uma das tarefas, pois à medida que exigimos prazos dos nossos alunos, temos que cumprir com o prazo anunciado na Agenda Disciplina, que deixa claro para o aluno quando ele terá o feedback do seu Tutor EaD.

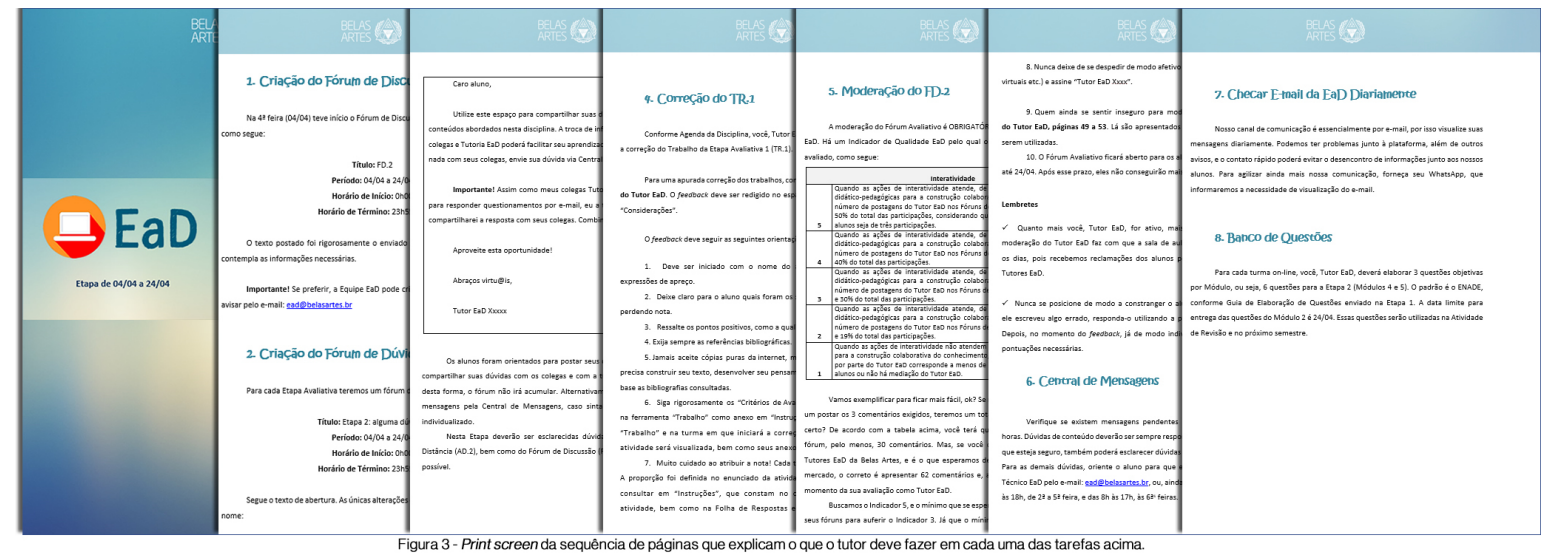

Para conduzir os fóruns de discussão avaliativos, os Tutores EaD recebem treinamento e métricas qualiquantitativas, definidas por Jacqueline Lameza (LAMEZA; NEVES; FERNANDES, 2013) e que garantem uma mediação de qualidade com foco na aprendizagem colaborativa. $O$ aluno, por sua vez, fica ciente dos critérios de participação e avaliação nos fóruns de discussão sempre no seu início. No momento da avaliação do fórum de discussão, o Tutor EaD tem a oportunidade de avaliar a quantidade e a qualidade do conteúdo postado, já que durante a mediação do fórum seu papel é de condutor, de motivador (Lameza, 2017).

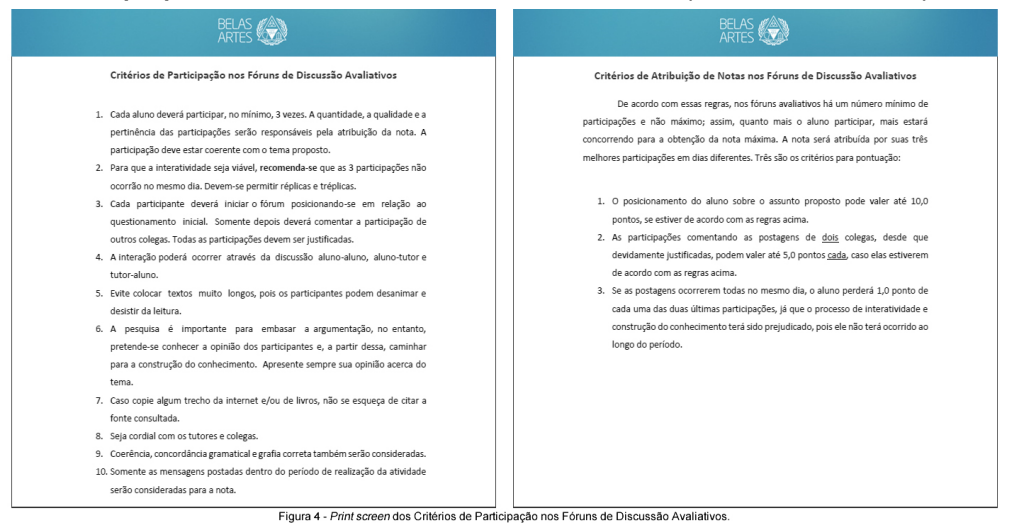

O mesmo procedimento é seguido para a condução e a correção dos trabalhos. Existem regras claras para os feedbacks intermediário e final, pois em atividades de maior complexidade, que envolvem habilidades cognitivas de nível superior e, geralmente, permitem mais de uma solução, o feedback deve ser oferecido durante a realização da atividade e não apenas após sua conclusão, como afirma Filatro (2008). O feedback deve evidenciar ao aluno que seus textos e/ou mensagens foram lidas e, principalmente, justificar a perda de nota. Tampouco podem ser atribuídas notas máximas ou notas iguais à toda a sala sem justificativa plausível, concordando com Lameza (2017). Chamar o aluno pelo nome e fazer uso de linguagem afetiva demonstram respeito e consideração pelo seu esforço, que merece ser reconhecido, ainda que seu desempenho tenha deixado a desejar, corroborando com Carlini e Tarcia (2010), quando afirmam não ser interessante submeter os alunos a situações de desconforto por causa de uma crítica mais severa, pois eles podem sentir-se rejeitados e desistir do curso. 


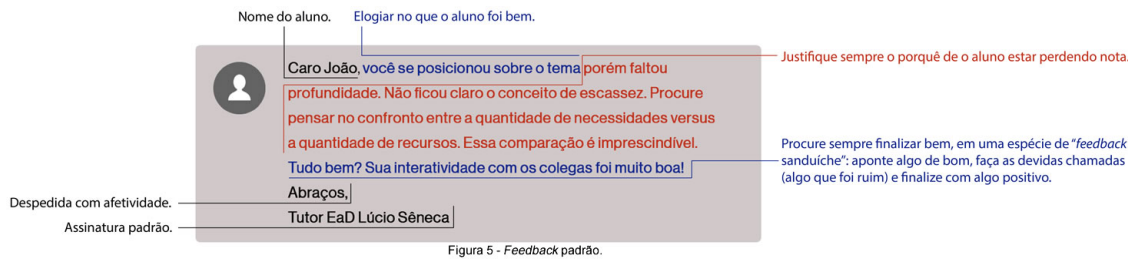

Para garantir a qualidade desejada, o Centro Universitário Belas Artes de São Paulo adotou e adaptou os Indicadores de Qualidade EaD propostos por Lameza (2013). Para os Tutores EaD foram considerados itens como interatividade, afetividade, tempestividade, feedback, criação de atividade avaliativas, elaboração da avaliação presencial, cumprimento do modelo e organização da sala de aula virtual, bem como o cumprimento de prazos e a formação e experiência do Tutor EaD para que a condução da disciplina ocorra com segurança. Nestes indicadores, se a nota atribuída for inferior a 3, o Tutor EaD é encaminhado para capacitações específicas. As capacitações específicas são justificadas, visto que, ao ser contratado o profissional passa pelo Curso de Formação de Tutor EaD, uma formação geral, sem identificar as fragilidades do profissional, que somente são notadas no dia a dia.

\subsection{Suporte técnico e educacional}

Os recursos administrativos são percebidos pelos alunos como tudo o que corresponde ao conjunto das ações, recursos e serviços disponibilizados ou exigidos pelo relacionamento entre aluno e instituição. Embora muitos desses aspectos estejam intimamente relacionados com o desenvolvimento das atividades acadêmicas, o aluno geralmente os percebe como questões administrativas ou burocráticas, como afirma Loyola (2009). Neste sentido, a equipe de suporte coloca-se à disposição dos alunos para quaisquer dúvidas que não sejam de conteúdo, pois estas são de responsabilidade dos Tutores EaD. $O$ atendimento ocorre presencialmente, por email e telefone. O tempo de resposta é de, no máximo, 24 horas úteis. Nos cursos de pósgraduação, há um reforço por meio do WhatsApp, 7 dias por semana. Nos dias de entrega de atividades, quando ocorre maior demanda dos alunos, o horário de atendimento é estendido e somente é encerrado quando não há mais questionamentos. A linguagem afetiva e a urgência no atendimento são questões fundamentais, pois um problema técnico e/ou de entendimento não pode impedir ou dificultar que o aluno dê continuidade aos seus estudos deixando de entregar uma atividade. Para melhor entendimento do aluno, assim que ele inicia um curso ou disciplina EaD, passa por um Módulo Introdutório, um período de integração e ambientação para que ele possa se familiarizar com a plataforma e, sem o compromisso com nota, testar ferramentas e recursos, além de já ir interagindo com seus colegas e Tutores EaD. Tudo isso tendo como pano de fundo o Manual do Aluno que, passo a passo, detalha cada fase. Para apoiar este Módulo Introdutório, oficinas presenciais são ofertadas em vários horários para que dentro de sua disponibilidade, o aluno escolha a melhor opção.

\section{CONSIDERAÇÕES FINAIS}

A Educação a Distância é uma realidade no Brasil e no mundo. A qualidade em EaD, neste sentido, é uma preocupação constante nas Instituições de Ensino Superior, seja pela qualidade, seja pela concorrência acirrada. Em uma sociedade líquida — onde uma necessidade hoje, agora, daqui duas horas já não é mais - o EaD se fortalece, pois é fundamental para a 
aprendizagem e para os processos de aperfeiçoamento, além, das facilidades de uso, flexibilidade e acesso. Assim, a utilização de métodos e ferramentas de gestão são essenciais para o alcance dos melhores resultados. É certo que implementar ISO 9001, em qualquer produto ou serviço, é sinal de melhoria contínua; e, assim, implementar sistema de gestão de qualidade, em educação a distância (cursos e disciplinas), por meio de uma administração eficaz, o resultado só pode ser: alunos satisfeitos com a gestão do curso, com os tutores e, principalmente, com o conteúdo, relevante e bem estruturado. Por fim, resultando maior competividade. No Brasil, o primeiro EaD com certificação ISO 9001, com 100\% dos seus processos certificados pelo órgão certificador ABNT, é o do Centro Universitário Belas Artes de São Paulo.

\section{REFERÊNCIAS BIBLIOGRÁFICAS}

ABED. Censo EaD.BR: relatório analítico da aprendizagem a distância no Brasil 2016. Curitiba: InterSaberes, 2017.

AKERLOF, George. The Market for "Lemons": Quality Uncertainty and the market Mechanism. Quarterly Journal of Economics, v. 84, n. 3, p. 488-500, 1970.

BRASIL. Decreto $n^{\circ}$ 9.057, de 25 de maio de 2017. Brasília, DF. Disponivel em: $<$ http://www.planalto.gov.br/ccivil 03/_ato2015-2018/2017/decreto/D9057.htm>. Acesso em: 29 mai. 2018.

CARLINI, Alda Luiza; TARCIA, Rita Maria Lino. 20\% a Distância - e agora? São Paulo: Pearson, 2010.

CAROLEI, Paula. Processo de criação de hipertextos e atividades. In: KENSKI, Vani Moreira. Design instructional para cursos on-line. São Paulo: Editora Senac São Paulo, 2015.

CORBETT, Charles J.; MONTES-SANCHO, Maria J.; KIRSCH, David A. The Financial Impact of ISO 9000 Certification in the United States: An Empirical Analysis. Management Science, v. 51, n. 7, p. 1046-1059, 2005.

CORDEIRO, Leonardo Z. Elaboração do material videográfico: percursos possíveis. In: CORRÊA, Juliane Educação a distância: orientações metodológicas. Porto Alegre: Editora Artmed, 2007.

DIMARA, Efthalia; SKURAS, Dimitris; TSEKOURAS, Kostas; GOUTSOS, Stavros. Strategic Orientation and Financial Performance of Firms Implementing ISO 9000. International Journal of Quality \& Reliability Management, v. 21, n. 1, p. 72-89, 2004.

FILATRO, Andrea. Design instrucional na prática. São Paulo: Pearson Education do Brasil, 2008.

FRANCO, Marco Antonio M. Elaboração de material impresso: conceitos e propostas. In: CORRÊA, Juliane. Educação a distância: orientações metodológicas. Porto Alegre: Editora Artmed, 2007.

LAMEZA, Jacqueline de O. O tutor a distância e a mediação eficaz de fóruns de discussão avaliativos. In: TOROVA, Andreza Gessi: BOCCIA, Margarete Bertolo. Pedagogia e a modalidade a distância. São Leopoldo: Editora Oikos, 2017.

LAMEZA, Jacqueline de O.; NEVES, Ana C.; FERNANDES, Cibele R. Indicadores de qualidade EaD: uma avaliação dos atores envolvidos nos cursos de graduação a distância. Disponível 
em: . Acesso em: 20 de maio de 2018.

LOYOLA, Waldomiro. O suporte ao aprendiz. In: LITTO, Frederic M.: FORMIGA, Marcos. Educação a distância: o estado da arte. São Paulo: Pearson (2009).

MILGROM, Paul; ROBERTS, John. Economics, Organization \& Management. 1a. ed. Upper Saddle River: Prentice-Hall, 1992.

PINDYCK, Robert; RUBINFELD, Daniel. Microeconomia. São Paulo: Makron, 1999.

RODRIGUES, Francisco C. T. S.; NAKAMURA, Wilson T.; MARTIN, Diógenes M. L. Impacto de longo prazo da certificação ISO 9000 no desempenho financeiro: um estudo com dados em painel das companhias abertas brasileiras no período 1995-2006. Anais. SIMPOI 2008. Fundação Getúlio Vargas, 2008.

SANTOS, Letícia; ESCANCIANO, Carmen. Benefits of the ISO 9000: 1999 System. International Journal of Quality \& Reliability Management, v. 19, n. 3, p. 321-334, 2002.

SILVA, Robson S. Gestão de EaD: educação a distância na era digital. São Paulo: Editora Novatec, 2013.

WITHERS, Barbara; EBRAHIMPOUR, Maling; HIKMET, Neset. An Exploration of the Impact of TQM and JIT on ISO 9000 Registered Companies. International Journal of Production Economics, v. 53, n. 2, p. 209-216, 1997.

. Does ISO 9000 Certification affect the Dimensions of Quality used for Competitive Advantage? European Management Journal, v. 18, n. 4, p. 431-443, 2000. Impacts of ISO 9000 Registration on European Firms: A Case Analysis. Integrated Manufacturing Systems, v. 12, n. 2, p. 139-151, 2001. 